\title{
Art, experience and alterity: reflections in the horizon of ethical and aesthetic education
}

\section{Arte, experiência e alteridade: reflexões no horizonte da educação ético-estética}

\section{Arte, experiencia y alteridad: reflexiones en el horizonte de la educación ético-estética}

\begin{abstract}
Maria Regina Johann ${ }^{1}$ iD
${ }^{1}$ Universidade Regional do Noroeste do Estado do Rio Grande do Sul, Ijuí, Rio Grande do Sul, Brasil.

Autora correspondente:

Nome: Maria Regina Johann

Email: maria.johann@unijui.edu.br

Como citar: Johann, M. R. (2021). Arte, experiência e alteridade: reflexões no horizonte da educação ético-estética. Revista Tempos e Espaços em Educação, 14(33), e15315. http://dx.doi.org/10.20952/revtee.v14i33.15315
\end{abstract}

\begin{abstract}
Oriented by the theoretical perspective of philosophical hermeneutics, this text addresses the ethical and aesthetic dimension of education, and it has the arts teaching as a reflexive field, emphasizing the artistic experience as a possibility for knowledge and self-awareness beyond the instrumental rationality frameworks. I emphasize, therefore, the artistic experience as an opportunity of (re) approximation among the student, the work and the artist as a way of selfinvestigation in the field of authorship, with reference to the experimentation of the artistic game and the tensions of the creative process. This creative process triggers a dialogue, which would be in the basis of ethics, since the moral action would be based in the process of co-creation of the aesthetic experience in relation to the work of art.
\end{abstract}

Keywords: Philosophical hermeneutics. Aesthetic experience. Co-creation. Art Teaching.

\section{RESUMO}

Orientadas pela perspectiva teórica da hermenêutica filosófica, as reflexões apresentadas emergem de reflexões à luz de leituras e pesquisas bibliográficas, especialmente referenciadas em HansGeorg Gadamer. O texto aborda a dimensão ético-estética da educação, tendo como campo reflexivo o ensino de artes, enfatizando a experiência artística como possibilidade de conhecimento e autoconhecimento para além dos enquadramentos da racionalidade instrumental. $O$ artigo destaca, por isso, a experiência artística como uma possibilidade de (re)aproximação entre o aluno, a obra e o artista, como forma de investigação de si mesmo no campo da autoria, tendo como 
referência a experimentação do jogo artístico e as tensões do processo criativo. Esse processo criativo desencadearia um diálogo, o qual estaria na base da ética, uma vez que o agir moral se fundamentaria no processo de cocriação da experiência estética em relação à obra de arte. Este conhecimento sensível tem potencial formativo e, portanto, se justifica no âmbito da educação escolar, de modo especial, no ensino das artes.

Palavras-chave: Hermenêutica filosófica. Experiência estética. Cocriação. Ensino de Arte.

\section{RESUMEN}

Guiado por la perspectiva teórica de la hermenéutica filosófica, este texto aborda la dimensión ético-estética de la educación, teniendo la enseñanza de las artes como un campo reflexivo, enfatizando la experiencia artística como una posibilidad de conocimiento y autoconocimiento más allá del marco de la racionalidad instrumental. Por lo tanto, destaca la experiencia artística como una posibilidad de (re)aproximación entre el alumno, el trabajo y el artista como una forma de investigarse en el campo de la autoría, teniendo como referencia la experimentación del juego artístico y las tensiones del proceso creativo. Este proceso creativo desencadenaría un diálogo, que estaría en la base de la ética, ya que el acto moral se basaría en el proceso de co-creación de la experiencia estética en relación con la obra de arte.

Palabras clave: Hermenéutica filosófica. Experiencia estética. Co-creación. Enseñanza de arte.

\section{INTRODUÇÃO}

Esta escrita visa a contribuir para o debate acerca da arte e seu ensino no horizonte da hermenêutica filosófica. Para tanto, destaca-se a experiência estética como uma dimensão relevante da arte/educação, na medida em que a especificidade desta área de conhecimento é o estudo acerca da arte e dos diversos âmbitos da cultura humana por meio da inter-relação entre teoria e prática. A dimensão da estética é tema amplo e vastamente pesquisado na educação; sendo assim, este texto não ignora tais estudos, contudo objetiva destacar as possíveis contribuições da estética como campo de experiência que potencializa a reflexão de cunho também ético. Tematizando tais aspectos, busca-se ver em que medida essa perspectiva fomenta a reflexão acerca da condição humana e mostra-se potente para ampliar as noções de mundo humano que a própria arte carrega, ampliando-se, assim, as possibilidades do ensino e oxigenando as propostas pedagógicas dado que o professor oportuniza vivências artísticas que podem gerar a experiência ético-estética; experiência autoeducativa que tem na pergunta e na abertura seu princípio formativo. Reitera-se que essa perspectiva não ignora os avanços já produzidos na área, mas, talvez, contribua para enriquecê-los.

Essa abordagem nasce de pesquisas bibliográficas que têm nas obras de Hans-Georg Gadamer seu autor principal. Potencializa-se e se tensiona as ideias de Gadamer com pensadores e comentadores de suas obras, de modo especial Hans-Georg Flickinger e Nadja Hermann. Inspira-se em tais autores para abordar a noção de arte como linguagem e seu potencial para enriquecer as práticas da educação artística escolar. Desde que sustenta o caráter poético da arte, argumenta em favor de uma educação de viés ético-estético, pela abertura que a própria obra sugere e o encontro com o outro que ela oportuniza.

\section{A HERMENÊUTICA FILOSÓFICA E A PERSPECTIVA DA EDUCAÇÃO ÉTICO-ESTÉTICA}

A perspectiva da educação ético-estética pode ser vinculada à noção gadameriana de que educar é educar-se (Gadamar, 2000)! O pensamento de Gadamer sugere que, por meio do diálogo, realizamos um movimento de abertura à alteridade que é fundamental para o processo de compreensão e autocompreensão; visão que permite afirmar que nos constituímos humanos num processo intersubjetivamente tecido linguístico, histórico e culturalmente (Gadamar, 1999). 
$\mathrm{O}$ pensamento de Gadamer destaca a arte como uma linguagem que permite o acesso à verdade e dá à dimensão estética uma ênfase mediante sua potencialidade de abertura e reflexão. A verdade que a arte nos mostra não é dogmática, e conta sempre com a interpretação do sujeito, que, ao se encontrar com a obra, vive um encontro de horizontes: o seu, o da arte e o da tradição.

A experiência estética que a arte permite é uma possibilidade de autocompreensão e um alargamento da nossa relação com o mundo; proporciona pensar que por ela ampliamos visões e possibilidades de compreender e agir, na medida em que a arte oportuniza "[...] aprimorar nossa capacidade de escolha" (Hermann, 2010, p. 36). Da interpenetração entre a razão e o sensível, temos a dimensão ético-estética, proposta por Nadja Hermann, como a geradora das condições em que a razão especulativa não restrinja a imaginação e a sensibilidade. Os argumentos da autora voltam-se para uma perspectiva educativa que "[...] articule a criação do eu com nossa radical inserção no horizonte histórico, um mundo comum, em que compartilhamos as orientações da vida e os ideais de sociedades concretas (Hermann, 2010, p. 17).

A estética tem potencial formativo, uma vez que ela mobiliza os sentidos e a razão e, por isso, Hermann argumenta que "[...] da experiência estética aparece uma verdade que não é aprendida pelo conceito" (2010, p. 14). A autora recorre a Schopenhauer e Nietzsche, e corrobora a advertência que ambos fazem acerca da prioridade da razão, das justificações racionais do agir moral, de uma defesa da vontade e da intuição e, por conseguinte, alerta para a ilusão de que "[...] nosso acesso ao mundo das aescolhas éticas dispensaria a sensibilidade e a intuição" (Hermann, 2010, p. 15).

A dimensão estética é abrangente e, nesse sentido, a arte ganha relevância porque se apresenta como uma forma de suportar a verdade e a tragicidade da existência humana. Por meio de sua especificidade poética, a arte amplia as noções de mundo e deixa entrever a inter-relação entre os sentidos e a razão e, desse modo, abre uma brecha para reveremos a soberania da razão quando a questão diz respeito à aprendizagem. Neste sentido, a arte pode nos lembrar do caráter trágico e finito de nossa condição humana e, por isso, insistimos no aspecto do assombro que nos causa, pois, independentemente do tempo histórico, a obra oportuniza reflexão e gera estranhamentos.

A metáfora de que a arte é janela para o mundo (Johann \& Fensterseifer, 2021) nos serve para expressar o caráter de abertura da arte, que oportuniza ao intérprete sair do mundo ordinário e adentrar num mundo extraordinário, no qual diferentes aspectos podem se desvelar ou revelarse. Desse modo, a arte desloca nossa visão de mundo e abre possibilidades de alteridade. Este seu modo de ser comporta, além dos aspectos estéticos, também dimensões éticas, isso porque a arte não tem compromissos com verdades absolutas e tampouco com fins objetivos ou instrumentais e, por essa razão, ela surpreende e desconcerta. Destarte, essa autonomia libera o artista para apresentar, ao seu modo, diversas dimensões do mundo humano. Seguindo nesse raciocínio, podemos afirmar que, não raras vezes, somos golpeados pela obra artística, arrebatados por sua ideia/mensagem e nos sentimos perturbados, desconfortáveis. O (novo) horizonte que se espreita, via o artístico, possibilita outras miradas; portanto, a arte abre janelas que oportunizam olhares reflexivos e isso pode ser autoeducativo.

O encontro com o outro, que a arte oportuniza, é, antes de tudo, um encontro conosco mesmos, pois o outro apresenta-se, paradoxalmente, como espelho e lembrança de nossa própria humanidade. Dar-se conta disso nos puxa do caimento em nós mesmos, sacode nosso inautêntico viver e oportuniza, por vezes, a experiência de uma existência autêntica na medida em que autoriza a invenção de si mesmo, a cocriação na linguagem.

O outro, o desconhecido e o estranho, já nos alertou Flickinger (2014), são verdadeiros motores da reflexão desde quando instauram a pergunta e movimentam a compreensão. Isso significa que a educação necessita considerar a pergunta (o estranhamento) como chave para a aprendizagem, à proporção em que aquilo que vem ao nosso encontro no estranhamento 
desconcerta e lembra-nos que a vida é tortuosa e são diversos os modos de expressá-la e significála; a arte, seria, então, somente mais um deles.

Neste sentido, subentende-se que a arte é uma, entre tantas linguagens que os humanos se valem para se expressar, ou seja, nem mais e nem menos importante do que as demais, como a ciência, por exemplo. Somente que a sua especificidade, de origem poética, potencializa o âmbito da abertura aos mais diferentes modos de expressão. Nesse sentido, o artista antecipa, via o sensível, uma visão de mundo que inter-relaciona realidade e imaginação, e torna visível algo que habita o mundo humano. A imaginação complementa aspectos da realidade vivida e, por meio da fantasia, é possível manifestar outros modos de compreender e interpretar a existência. É neste sentido que a estética produz afetação e tem força para influenciar a nossa moral, porque, ao imaginar "como poderia ter sido", nós manifestamos outros valores, outras possibilidades de fazer mundo comum ou sermos-uns-com-os-outros, e isso tem a ver com a ética entre os humanos e, desses em relação ao meio.

Quando se argumenta que a arte tem relevância na nossa formação, significa dar ênfase à noção de que, por meio do estético, se abrem outras oportunidades compreensivas com grande potencial formativo. Na perspectiva da arte, não se trata de possíveis mensagens, mas, sim, de ampliar visões de mundo por meio da especificidade da obra artística. Diferentemente da ciência, que, por sua natureza instrumental precisa manter objetividade e coerência com o método, a arte é livre para, inclusive, enriquecer a própria ciência. É neste sentido que a crítica de Gadamer (1999) se endereça à estetização da arte; de uma certa tendência em conformá-la em categorias e estilos estéticos, como se um método analítico ou um enquadramento estilístico deem status à obra. Neste sentido, Gadamer (2010) sugere pensarmos acerca do risco de transformarmos a arte numa manifestação que já nos chega via um discurso pré-formatado, um manual que contém uma "verdade". Esta advertência relembra a dimensão ontológica da arte, o que não significa ignorar a tradição de sentidos que a obra carrega. Ao contrário, Gadamer $(1999,2010,2004)$ destaca a objetividade histórica da obra artística e reconhece que cada tempo tem a sua consciência histórica que, inclusive, influência a nossa própria leitura acerca da obra. Neste horizonte, menciona que a arte permite que nos olhemos no tempo presente, ao mesmo tempo em que vemos o que foi. Por intermédio da obra espreitamos a nossa própria condição humana por meio dos vários ângulos que deixam entrever diversos modos de ser ou poder ter sido (Gadamer, 2010).

Por tudo isso, podemos inferir que a arte é um modo de conhecimento sensível e, enquanto abertura à experiência estética que oportuniza, ela permite viver o conhecimento ao modo éticoestético, posto que instaura uma pergunta de cunho universal em perspectiva individual. Destarte, Gadamer afirma a hermenêutica filosófica como uma ideia central de sua teoria, uma vez que a abertura à reflexão é um princípio do compreender, é uma anterioridade que nos constitui em humanos, e o que podemos declarar acerca de nós mesmos está encharcado de consciência histórica. Em certa medida, essa ideia tem inspiração em Heidegger (1989), que assevera ser a compreensão um distintivo dos humanos; nós compreendemos que compreendemos.

A compreensão emerge do questionamento, da abertura ao novo. A pergunta, portanto, movimenta a compreensão, e nisso se reconhece que a experiência ontológica se dá antes de toda atividade reflexionante. Nessa direção, tem-se a experiência estética como algo para além do conceito, na medida em que o sensível, o poético e, inclusive, as emoções, encontram um lugar, porque "[...] o pensum propriamente dito da hermenêutica filosófica seria aquele de denunciar e desvelar a falsa soberania do conceito" (Flicklinger, 2000, p. 28).

Ana Mae Barbosa (2009, p. 21) também já alertou para o fato de que a arte é "[...] uma linguagem aguçadora dos sentidos, transmite significados que não podem ser transmitidos por nenhum outro tipo de linguagem, como a discursiva e a científica". Essa sua especificidade permite pensar no que pode a arte produzir enquanto experiência ético-estética, posto que não privilegia o conhecimento da ciência tampouco a fala ou a escrita, mas acolhe os diferentes modos de 
manifestação humana, aspectos evidenciados especialmente na arte contemporânea ao modo como o artista inter-relaciona palavra, corpo, sons, movimento; recontextualiza e hibridiza objetos e artefatos da cultura visual produzindo, inclusive, limites tênues entre arte e outras dimensões do cotidiano, como a propaganda, a moda e o design. Esta amplitude da arte tem potencialidade interdisciplinar e, nesse sentido, ela estaria descompromissada "[...] com a rigidez dos julgamentos que se limitam a decidir o que é certo e o que é errado [...]" (Barbosa, 2009, p. 21), e é nesse horizonte que pode desvelar verdades que fogem da racionalidade instrumental, ampliando as experiências de sentidos e de oportunidades formativas.

Trazendo esses aspectos ao horizonte hermenêutico filosófico, destacamos que "[...] cada linguagem expressiva precisa ser exposta à interpretação e, com isso, a um processo de configuração de um sentido possível, com pretensões de verdade própria" (Flicklinger, 2000, p. 29). Se, portanto, a arte tem este potencial de abertura, parece convir que isso seja "explorado" também no horizonte da educação, oportunizando o florescimento dos sentidos como dimensões aprendentes. Nesta perspectiva, os sentidos não ficam esgotados, mas põem-se em contínua possibilidade e, assim, considera-se que a busca de uma verdade inquestionável é o perigo de deixar tantas outras possibilidades excluídas.

A hermenêutica filosófica aposta no encontro do intérprete com a obra e, nesta direção, trabalha com o pressuposto de que a verdade que a arte nos permite não está na dependência da afirmação de um dos lados - obra ou intérprete - senão de um acordo que nasce da fusão de horizontes decorrente deste encontro. Nessa perspectiva, a verdade está sempre na confluência dos acordos, na intersubjetividade dialógica, na finitude da linguagem e, por isso, é aberta, reflexiva, acordada e não predicativa. Quando, no entanto, falamos em objetividade, é a isso que nos referimos, não à relação standard sujeito-objeto, mas, sim, que sujeito e obra sejam levados em consideração, pressupondo uma disposição à abertura de novos sentidos.

Nessa dialética, a arte como uma experiência de acesso à verdade evidencia exatamente algo que somente por meio dela acontece: a estruturação do nosso mundo pela manifestação de uma verdade que não tem pretensões de ser absoluta e que sempre se atualiza (Gadamer, 1999). Essa característica é um âmbito ético intrínseco à obra e à relação que dela emerge, uma vez que pressupõe uma postura reflexiva. Ademais, a arte "[...] não exprime nem dá testemunho de um mundo constituído fora dela ou independentemente dela; ela própria abre e funda um mundo" (Vattimo, 1996, p. 125), e, então, mostra, a seu modo, algo que requer disposição e entrega. Corrobora-se a noção de que arte não reproduz, mas cria mundos, o que implica admitir uma certa autonomia da obra, e o que ela expõe é algo próprio que não representa a realidade, mas, sim, a recria. É neste sentido que a obra funda um mundo (Gadamer, 2010) ${ }^{1}$.

A hermenêutica admite a interdependência entre obra, história e intérprete. Inclusive Gadamer (1999; 2004) destaca a dimensão da consciência histórica como um aspecto importante da interpretação, posto que os sentidos individuais são tecidos na dialética e historicidade do mundo e, assim, aquilo que pensamos está carregado de tempo, história e de tradição.

\section{A ARTE NO HORIZONTE DE UMA EDUCAÇÃO REPUBLICANA E DEMOCRÁTICA: EXPERIÊNCIA E ALTERIDADE}

As linguagens artísticas têm uma especificidade que necessita ser levada em consideração quando se pensa o ensino; um dos aspectos diz respeito à articulação entre a teoria e a prática, que são dimensões fundamentais da aprendizagem artística. Neste sentido, o ato criador da arte

\footnotetext{
${ }^{1}$ Admite-se que a obra também traduz aspectos do tempo/espaço interpretado pelo artista e, inclusive, um sentimento de época que se explicita em diferentes manifestações artísticas, desde os primórdios até hoje.
} 
escolar ${ }^{2}$ adquire destaque, pois tem um potencial significativo, considerando que a criação exige a mobilização de conhecimentos, procedimentos e materialidades, além da capacidade de imaginar e transformar. Mesmo com contornos escolares, a criação artística que o aluno experimenta pressupõe a pesquisa de hipóteses, a testagem de materiais e a expressão de ideia e conceitos. Tais aspectos têm potencial ético-estético relevante para a compreensão de especificidade da própria arte, na medida em que o fazer artístico permite a instituição de um fundamento, de uma origem e o encontro com o outro, que nos vem por meio do estético, oportunizado via criação.

Neste sentido, a arte escolar tem força de abrir à experiência e, por isso, a especificidade das linguagens artísticas exigem a vivência de processos criativos. Assim, mais do que tematizar a estética, é preciso experienciá-la para compreender a especificidade da criação e da autoria. Exemplificamos afirmando que todo o discurso sobre a dança não equivale a um passo de dança. Essa especificidade é um dos desafios da arte na escola, por isso a experimentação é imprescindível à compreensão da arte como linguagem e poética. À vista disso, entendemos que a própria história da arte fica insuficiente se o aluno não experimentar o ato criador. Reafirmamos que a arte é uma linguagem expressiva que se dá na cotidianidade da vida, e, desse horizonte, não se basta nos discursos que a explicam; ela também requer vivência e experienciação. Nessa perspectiva, Gadamer (1999) alerta para a ênfase nos aspectos iconográficos da História da Arte como um thelos de acesso à verdade da arte. $^{3}$ Igualmente já expressa a suspeita "[...] em relação a toda fundamentação teórica do saber que negligencie a experiência ontológica primordial, em que mergulhamos no nosso relacionamento imediato com o mundo" (Flicklinger, 2000, p. 27).

Diante de tais considerações, parece-nos adequado que a educação incentive a pesquisa artística e a vivência de diferentes linguagens, aproximando, em certa medida, o aluno daquilo que o artista realiza - embora em contextos e intenções distintas -, possibilitando, de certo modo, a compreensão e a experimentação do jogo artístico em perspectiva escolar. Entende-se que isso pode contribuir para que o aluno viva a tensão do processo criativo, trazendo para si aspectos do viver estético. Isso possibilita compreender que a arte é uma dimensão expressiva e cognitiva que se manifesta e se materializa por meio de diferentes procedimentos e materiais. Desse modo, as referências fornecidas pelo professor (e pela tradição) são relevantes, contudo insuficientes e, por isso, necessitam ser ampliadas, recontextualizadas e tornadas próprias.

Flickinger (2000) auxilia-nos a contextualizar essa especificidade da arte e da experiência que ela permite, sustentando que:

A obra de arte, não sendo alcançável única e exclusivamente através da lógica reflexionante, conclui-se que sua articulação e configuração esconda algo acessível somente àquele que sem compromissos, de antemão, controláveis pela reflexão - a ela se entregue. A arte exige-nos pela sua simples presença. Embora não diretamente expressa, sua finalidade parece pertencer ao seu modo de ser (Flicklinger, 2000, p. 32).

Esse modo próprio permite, inclusive, que na arte se acolha o desprezível e o marginalizado pelas demais áreas do conhecimento escolar, dando-Ihes relevância e visibilidade, de tal modo que, na experiência artística, a fantasia, o erotismo e as emoções também encontram um lugar (Hermann, 2010), pois, como já prenunciou o poeta, sobras e restos interessam...

Essa especificidade em perspectiva ao ensino artístico sugere que se articulem conteúdos conceituais, história da arte e pesquisa de criação por meio das diversas linguagens. e, é nesse

\footnotetext{
${ }^{2}$ Aqui refere-se à arte escolar como aquela que emerge de um contexto educativo que, embora dialoga com o universo artístico, não tem a pretensão de se constituir obra de arte, tal qual venha a ser para um artista.

${ }^{3}$ Também a arte que está no museu e nos acervos particulares não recupera seu lugar originário, comprometendo, de algum modo, sua compreensão, pois, aprisionada em ideologias de museus, ela fica desenraizada do contexto vital que Ihe dá origem, e passa a ter referência apenas pela "distinção estética", orientada pelo objetivo, função e significado do conteúdo (Gadamer, 1999).
} 
sentido que a experiência pode assumir um lugar privilegiado, uma vez que a arte requer articulação teórico-prática. Desse modo, o aluno vale-se dos conteúdos escolares e da própria tradição artística, tendo nas obras as referências e as inspirações, ao contrário de uma receita ou uma prescrição. Ao mobilizar-se para o processo de criação, o aluno recorre à história da arte, às pesquisas dos artistas, à tradição da área como pontos de partida para sua criação escolar. Isso é possível apreciando, observando, lendo, comparando, experimentando, refletindo, recontextualizando, hibridizando, inter-relacionando as imagens, os símbolos, os objetos, as ideias e os saberes. A partir do universo da arte, da obra e de uma determinada linguagem, é possível adquirir elementos para o desenvolvimento de uma poética pessoal inter-relacionada às questões específicas da área e do próprio cotidiano pessoal.

Reacorrer à tradição de uma área por meio da pesquisa e da experiência artística escolar é, nesse contexto, reconhecer a tradição e os preconceitos que o artista e a própria obra nos deixam; talvez a possibilidade de recolher e ressignificar o já instituído pela tradição histórica e convalidar em uma perspectiva própria, num contexto contemporâneo, ou seja, "[...] do sentido mobilizado e dinamizado pela produtividade do acontecimento histórico" (Melo \& Souza, 1988, p. 74). ${ }^{4}$ De certa maneira, é uma possibilidade de aceitar a experiência pré-reflexiva e ontológica da arte, da qual o aluno é herdeiro como membro legítimo de uma determinada cultura.

O reconhecimento do saber do outro, das coisas da tradição, tem uma inteligência, isto é, têm motivações. Quem sabe, nessa perspectiva, o aluno experimenta a força que a arte tem de colocar-nos na emergência de encontrar algo, de experimentar o caráter surpreendente da revelação do mundo, constatando que o conhecimento não se limita à ciência. Isso não significa, por sua vez, uma oposição a ela, senão de resistência ao seu privilégio cultural (Gadamer, 1999).

Essa noção possibilita a compreensão ética de que os lugares de determinados saberes são proposições históricas, culturais e intersubjetivas. Não se admira, portanto, que a arte ocupe um lugar marginalizado em muitas escolas, pois, muitas vezes, os próprios professores ignoram, como parte do ensino, a tradição e a especificidade artística, dado que se deslumbram com a racionalidade instrumental e com a necessidade de encontrar verdades (absolutas) para tudo. Com isso, se esquece que a boniteza da arte é, ao mesmo tempo, assombro que ela oportuniza pela constante lembrança que nos deixa, de "[...] ser a mais peremptória advertência à consciência científica no sentido de reconhecer seus limites" (Gadamer, 1999, p. 33).

Uma relação fenomenológica com a arte instaura um sentimento (ético) de pertencimento desde que não institui uma relação sujeito-objeto, mas uma relação dialética entre o sujeito e a obra, que deixa marcas de uma acontecência que exige a consideração do outro, de algo além de nós. Essa abertura gera uma cumplicidade, podendo instaurar um sentimento de pertença, entendido por nós como ético e formador, o que significa não tomar sua verdade como moral a ser assimilada, mas como um vir à razão.

Intransponível e transformadora, a experiência estética, vivida na escola, pode alçar o aluno à reflexão de si próprio no embate da experiência autoral. Nisso adquire uma dimensão ética porque permite o agir ao abrir-se ao diálogo com a obra e, abrindo-se ao diálogo, admite a instauração da razão dialógica, território do agir moral. Aceitar o convite insistente que a arte nos faz, é deixar ser sugado para dentro dela mesma, como observa Flickinger (2000), e tomar a liberdade de acessar um mundo novo e alheio.

É o choque entre o nosso mundo de vida e a promessa desse novo mundo possível, o que nos leva à experiência de uma profunda irritação. Irritação que nos impele a um posicionamento também novo, a um modo de abrir-nos, procurando lugar dentro do novo espaço. Isso se dá 
através da descoberta e do desmascaramento de nossos próprios hábitos, interesses e paixões pessoais, orientadores das posturas anteriores (Flicklinger, 2000, p. 33).

A linguagem expressiva da arte tem a força de interrogar padrões, valores, concepções e gostos porque ela trans/forma, exigindo-nos reflexão. Diante dela nos deparamos, por exemplo, com vários conceitos de belo e feio, e por eles podemos pensar nos valores que contornam nossas vidas e imprimem identidades, pertencimentos ou exclusões. Podemos questioná-los não somente para desconstruí-los, mas para compreender que são proposições. Com as questões da arte temos como falar sobre o corpo, as emoções, a sexualidade, a sustentabilidade, a finitude, a totalidade, a tradição... Vale ressaltar, porém, que a arte permite tratar disso em outro campo de forças. Com ela sempre teremos a possibilidade de interrogar: Por que não? ${ }^{5}$

$\mathrm{Na}$ vivência artística, o aluno pode transfigurar a sua realidade, conhecer e, inclusive, transcender o instituído, elaborar as suas emoções e dar visibilidade às suas percepções. Isso se dá a partir da capacidade instituinte da imaginação humana em tensionamento com contextos e elementos históricos, porque na arte algo emerge à luz, e isso é o que chamamos verdade (Gadamer, 2010). Aquilo que vem em perspectiva do aluno no encontro com a obra é um conhecimento específico que nasce da fusão de horizontes; é a sua cocriação no horizonte histórico da obra. Nesse caso, ele é autor e protagonista de sua palavra; por isso, acolhemos a ideia de Gadamer (1999) de que a arte pode produzir a riqueza de viver a experiência como experiência na medida em que proporciona uma relação sem objetificações, podendo viver uma verdade que somente a própria experiência estética oportuniza.

A potencialidade da experiência ético-estética está em colocar o aluno diante da obra e deixar que "se contamine", que transbordem possibilidades, pois a abordagem instrumental assume uma dimensão secundária para um professor hermeneuta que compreende a força instituinte da linguagem artística e abre à experiência. Viver uma relação dialógica com a obra é salvá-la da objetificação (coisificação), e salvar também o aluno da relação pedagógica empobrecida de autoria. Isso porque, enquanto excesso, a arte predispõe uma experiência que exige que nos coloquemos diante dela a seu modo: ela requer a ação e autoriza-nos a criar, trazendo-a em perspectiva própria, e isso nos parece uma potencialidade peculiar da educação em perspectiva da formação para a alteridade. A arte é terreno fértil da educação que perspectiva um princípio republicano e democrático, que visa o mundo comum ${ }^{6}$.

Nesse panorama, a experiência artística é um acontecer entre sujeito e objeto em que a arte e o intérprete (aluno) estão interligados, não sendo, por isso, um acontecimento puramente subjetivo ou instrumental, pois os que estão na experiência (aluno, obra e arte) não estão inertes. A arte coloca as suas questões e evidencia sua atualidade e historicidade nos preconceitos que a própria obra carrega. Sendo assim, o que a arte anuncia ou os acenos que envia é de si mesma; isso porque ela "[...] nos fala enquanto obra e não enquanto a transmissora de uma mensagem" (Gadamer, 2010, p. 174); essa é a objetividade da obra sobre a qual Gadamer chama a atenção.

Desse modo, o saber da experiência é, também, ético-estético, uma vez que, no encontro entre obra e intérprete (aluno), é necessário pôr-se em perspectiva da linguagem artística. A experiência artística permite-nos a autenticidade do conhecimento. Esse é um saber distinto do saber da ciência, nem mais nem menos importante, somente diferente e válido. O saber, construído na experiência, é individual, pessoal e, por isso, intransferível. É um “[...] saber que não pode

\footnotetext{
${ }^{5}$ Justamente porque a arte não está subsumida a um padrão estético é que ela pode rompê-los, a ponto de algo se apresentar como arte sem ter sido construído pelo artista, como foi o caso do objeto “Fontaine", que Marcel Duchamp enviou a uma exposição na França, em 1917. Ver Mink (1996).

${ }^{6}$ A República e a escola estão inter-relacionadas; uma pressupõe a outra. A república, "[...] como sendo a possibilidade política de enfrentar nossa aventura social [...]" (Brayner, 2008, p. 135). Desse modo, "[...] uma escola republicana deve atribuir competências referentes à participação dos indivíduos nos debates que decidem suas vidas" (Brayner, 2008, p. 24).
} 
separar-se do indivíduo concreto em quem encarna" (Larrosa, 2014, p. 32); por isso, a experiência possibilita um saber próprio, mas que conta com o instituído pela tradição. Assim, o conhecimento é uma herança que cocriamos ao nos escrevermos, pois "[...] só quem se escreve, tornando-se o poeta da sua própria vida, pode realmente escrever em consonância com o ditame, segundo o qual a canção é a existência" (Melo \& Souza, 1988, p. 80).

A paerspectiva ético-estética aposta na relação de produção de acordos e juízos que se dão na confluência da tradição e da atualidade, exigindo um acerto que depende do agir moral e dos sentidos - a cocriação da ética e da estética. Isso significa trazer para o âmbito da educação a dimensão da política, de algo que necessita do juízo e da ação, que precisa ser emitido e, portanto, não está dado independentemente de nossas ações e opiniões. O juízo pressupõe que não tem algo já dado como verdade, mas que tanto ela quanto as leis necessitam ser produzidas nos acordos intersubjetivos, em um tensionamento entre tradição e atualidade, entre passado e presente, em perspectiva de um mundo comum.

Nesse contexto, o ensino da arte pode potencializar experiências de protagonismo, posto que essa dimensão política e ético-estética (da ação e do juízo), exige de nós sempre novos sentidos, sem pretensões de instituir a verdade como certeza. Sua especificidade estética deixa sempre a possibilidade da cocriação, estando aberta às questões do aluno, à pluralidade dos sentidos, ao universo da imaginação. Com isso, ela nos leva a pensar na dimensão ética do mundo humano, uma vez que sua característica de espelho, diferentemente da ciência e da religião, nos abre para várias possibilidades e respostas. ${ }^{7} \mathrm{~A}$ arte alarga, portanto, nossa percepção de mundo porque acrescenta nele dimensões próprias (estéticas) que se permitem estar na dependência do gosto, deixando que a verdade sempre se reconfigure na perspectiva dos juízos e dos acordos históricos e culturais.

É desse ponto de vista que criticamos a perspectiva escolar que institui uma relação entre o aluno e a arte de absoluta liberdade, uma vez que na ausência de proposições o aluno está órfão, solto em suas próprias referências ${ }^{8}$, pois o ensino "[...] não pode ser apenas improvisação e espontaneidade e requer encontro com obras e trabalhos reflexivos sobre a atividade" (Charlot, 2013, p. 218). Assim, mesmo no horizonte da arte contemporânea em que a apropriação e a improvisação são aspectos recorrentes, é necessário, por parte da abordagem escolar, um olhar crítico sobre o trabalho do artista, possibilitando ao aluno o questionamento sobre o que é arte e quem é o artista, para que se problematize o amplo universo de proposições, empoderando, assim, a pergunta pelas motivações e/ou razões de que algo se alce com pretensões artísticas. É ponderável, no entanto, reconhecer que o artista contemporâneo não somente democratizou a acesso à obra, mas também trouxe para seu horizonte temas emergentes da sociedade atual possibilitando, dessa forma, a reflexão, a desconstrução e a ressignificação de valores, padrões e visões de mundo; noções que enriquecem a educação e permitem a reconvalidação de valores e a reestruturação de mundos.

A partir dessa expectativa é que observamos que, na ausência do professor e de uma proposição de ensino, o aluno fica com sua possibilidade de compreensão restrita às suas opiniões, contextos, valores, culturas e saberes; da mesma forma, à concepção de ensino, que instrumentaliza a arte, evidenciando que a verdade da obra já está dada antecipadamente pelo próprio professor, pelo livro didático ou por uma função utilitária; também distancia o aluno de uma vivência ético-

\footnotetext{
${ }^{7}$ Nesse contexto, a noção de espelho diz respeito não àquilo que reflete, mas àquilo que permite ver a si mesmo, com a noção de que sua imagem espelha um mundo, tempo-espaço atrás de si mesmo.

${ }^{8}$ Essa característica era marcante na pedagogia da livre-expressão (evidenciada nos anos 70 e 80), mas que ainda deixa seus resquícios, especialmente na prática de professores da Educação Infantil e Anos Iniciais do Ensino Fundamental, tempo/espaço da educação básica em que se tem pouca interlocução com professores formados em artes.
} 
estética, pois a instrumentalização da arte impede a experiência, limita a percepção da arte como arte e define que ela tem uma utilidade $!^{9}$

Essas perspectivas restringem a experiência ético-estética, porque engessam a ação e a emissão de juízos, subestimando o potencial cocriativo do aluno e, ainda, limitam a experiência da alteridade, considerando que a obra carregaria uma verdade que independe do intérprete. Já a hermenêutica gadameriana quer assegurar um espaço de jogo que o intérprete precisa preencher na relação com a obra. Na circunstância do "jogar e ser jogado" é que Gadamer (2010) visualiza a possibilidade de a experiência estética acontecer, trazendo consigo a possibilidade de um agir éticoestético.

Assim, do ponto de vista do professor como hermeneuta e mediador, espera-se a postura de quem "democratiza a arte" e amplia as vivências com ela, uma vez que

[...] a capacidade de olhar para o mundo atribuindo significados não nos é dada ao acaso, tampouco podemos esperar que a experiência com uma determinada imagem nos capacite para ser bons leitores, embora seja uma (ótima) chance de crescer nessa direção. Assim, o trabalho do arte-educador na contemporaneidade assume o importante compromisso de mediar as relações de aprendizagem com a imagem, fomentando diálogos sobre os sentidos da arte em nossa vida (Azevedo, 2009, p. 337).

Corroboramos a noção de Azevedo (2009, p. 336), de que é necessário “compreender a arte como constructo histórico e social, sem perder de vista seu caráter mágico, provindo de sua natureza original [...]". Nisso a experiência estética tem valiosas contribuições, pois permite ao aluno a criação da arte escolar, trazendo para seu horizonte a possibilidade de instaurar a novidade da criação.

A compreensão desse aspecto requer, por parte do professor, o domínio de um campo de saber que pressupõe o reconhecimento "[...] de que na contemporaneidade a figura do artista assume a função de propositor de situações, de desafios que mobilizem o complexo de sensibilidade/inteligência do leitor, o qual deixa de ser mero contemplador passivo para assumir o papel de participante-reinventor" (Azevedo, 2009, p. 337).

Considerando tais aspectos, afirmamos uma vez mais que a arte possibilita que nos reconheçamos herdeiros de um mundo constituído de culturas e tradições. Tematizá-la em tempos/espaços educativos e permitir que ela venha em nosso horizonte de sentidos significa produzir um diálogo entre passado e presente, assegurando, então, um aspecto importante da formação: testemunhar o mundo e possibilitar ao aluno o acesso ao patrimônio artístico e cultural, traduzindo-o em perspectiva própria. Essa noção hermenêutico-filosófica permite apostar em uma educação ético-estética que, por sua vez, requer a mobilização do sujeito (aluno): o pôr-se em perspectiva da aprendizagem. Mobilizar-se para aprender significa "emitir a sua palavra", manifestar suas percepções, "perguntar suas perguntas". Significa, ainda, reconhecer que há uma tradição que nos é anterior e um patrimônio artístico e cultural que deixa acenos de experiências humanas, testemunhando dilemas, percepções, saberes, sonhos e apostas de uma determinada sociedade, por isso não é de bom senso ignorá-los. Nesse caso, lembramos que a hermenêutica filosófica já chamou a atenção para o cuidado em destituirmos a tradição de nossa vida (da educação), alertando para que sejamos mais modestos em nossas críticas a ela; a própria hermenêutica filosófica reconhece os limites de suas proposições quando chama à linguagem e à historicidade para nos lembrar a finitude.

\footnotetext{
${ }^{9}$ É recorrente, na educação escolar, o uso da arte para fins didáticos (desenhos pedagógicos, resquícios das Escolas Normais), por exemplo, a ilustração de passeios, de histórias, de mensagens para datas festivas. Também seu uso para decoração de ambientes, muitas das vezes com reproduções de arte de artistas em evidência.
} 
Evidenciando a atividade (o mobilizar-se) e o patrimônio como uma estrutura antropológica da educação, Charlot (2013, p. 229) adverte que "[...] desconectados ambos perdem seu valor educativo". Se, portanto, o nosso inacabamento realiza-se pela educação em um processo em que "se humaniza, se socializa, se singulariza", então ele apenas funciona quando se articula em perspectiva própria, em que o sujeito se educa em razão de um conteúdo/saber/patrimônio que reconhece (admite), que traz para si (Charlot, 2013).

De certo modo, é o que Gadamer (1999) nos lembra quando salienta que compreender é "um pôr-se de acordo sobre algo"; aspecto que destacamos como sendo a centralidade do processo de compreensão; isso significa a constituição da própria aprendizagem do sujeito. $O$ agir impõe-se, então, como uma condição, uma anterioridade da aprendizagem, independente da área de saber; é o próprio movimento de conhecer.

Para Charlot (2013), a estrutura antropológica (atividade e patrimônio) nutre o movimento da educação do homem, isso por que

Não há educação se o educando não mobiliza a si mesmo, não faz uso de si mesmo como um recurso, isto é, não entra em atividade. Portanto, não há educação artística se a criança não faz arte: essa é a verdade da corrente contemporânea. Mas tampouco há educação se o educando não encontra um patrimônio, isto é, obras, práticas, normas da atividade, que foram criadas pelas gerações anteriores. Portanto, não há educação artística se o aluno fica trancado na sua própria atividade, sem contato com as obras de arte e com as normas específicas que as possibilitem (Charlot, 2013, p. 229).

O que Charlot (2013) reivindica para que o movimento da educação se realize, relacionamos como os preconceitos e a tradição evidenciados por Gadamer (1999), pois, sem algo instituído como verdade (mesmo que provisória), sobre o qual nos reconhecemos, não é possível a formulação de perguntas e a emissão da opinião ou juízo.

Por isso a perspectiva pedagógica, que não passa pelo crivo da comunidade de saber à qual pertence, deixa a desejar em suas tarefas educativas e, inclusive, em seus propósitos republicanos e democráticos. Da mesma forma, uma vivência escolar que não dialoga com as questões do aluno e ignora o contexto no qual foram produzidas, desmerece o caráter político da educação e desrespeita a condição de menoridade do aluno, ignorando seus direitos de aprendizagem. Tal perspectiva inibe a possibilidade de experiência ético-estética, de um agir moral e estético e, por isso, no ensino da arte é ponderável considerar que

A espontaneidade e a criatividade não são pontos de partida, ao contrário do que pensa o senso comum. São feitos de uma educação que proporciona vários modelos de atividade, a serem adaptados, criticados, misturados, combinados, superados. O que faz um texto, um objeto ou um evento ser arte é o olhar que o constitui como tal. Aceitemos o princípio contemporâneo. Mas o olhar se educa (Charlot, 2013, p. 229).

Reiteramos, então, que, mesmo reconhecendo a precariedade das verdades humanas, é preciso admitir que necessitamos tomá-las por válidas (mesmo que provisoriamente), pois foram convalidadas por sujeitos concretos e carregam consigo o bom-senso do mundo da vida, bem como o reconhecimento da tradição (isso não desmerece as críticas a ela endereçadas). Novamente insistimos que isso não significa fixá-las, mas compreender justamente o contrário - que as verdades necessitam de convalidações, de acordos políticos, de um permanente reconhecimento intersubjetivo, dos quais professores e alunos também fazem parte.

Desmistificar a ciência e as verdades absolutas significa uma abordagem que não somente apresenta os conteúdos da tradição, mas permite compreender as razões pelas quais alguns saberes são universais e validados por ela. Isso quer dizer apresentar a tradição da área (para que o aluno entenda sua construção e sentido histórico) e implica dar subsídios ao aluno para compreender as 
motivações de sua própria aprendizagem, buscando razões para se inserir nesse debate e dando continuidade à reconstrução de saberes. Essa é uma aposta na ação visando à cocriação dos saberes.

Desse modo, a própria tradição do ensino vai se legitimando e, no caso das artes, certos artistas e obras ganham mais visibilidade, muitas vezes porque estão na dependência do gosto, do conhecimento e da qualidade da formação do próprio professor. Isso denota que a arte na escola está na dependência dos saberes, dos gostos do professor e do território demarcado pelo currículo escolar. Por isso, admite-se a necessidade de uma referência básica de currículo para que o aluno não fique alijado de certos saberes e experiências porque a escola ou o professor os desconhecem ou ignoram.

\section{CONCLUSÃO}

Deste horizonte de compreensão, a educação se faz quando o aluno encontra a educação/o educador e comunga o acesso ao patrimônio artístico e cultural num horizonte de diálogo e reflexão. Para conhecer e julgar é necessário tomar contato com a tradição (o instituído) e encontrar abertura para pensar e compreender em como ela se constituiu, quais os aspectos que a configuraram e por que algo se legitimou em determinado tempo e cultura. Conhecer sobre a arte para saber como ela se inscreveu no mundo humano é um dos objetivos do ensino, no entanto não é seu escopo máximo, por isso é fundamental permitir o acesso a respeito do que acontece atualmente e de suas perspectivas na educação. Assim, vivenciar a desconstrução e a recontextualização, características bastante presentes na arte contemporânea, são direitos de aprendizagem do aluno e isso requer um ensino que o empodere a partir de um saber teóricoprático, permitindo-lhe conhecimentos para se inserir na tradição, ao mesmo tempo em que aprende a estabelecer uma relação crítica com ela; movimento que o torne capaz de reconfigurar o horizonte de sentidos da obra, bem como da sua própria tradição.

Essa abertura permite a reconvalidação ou transgressão do instituído e pode ocasionar uma circunstância em que a experiência da alteridade aconteça, pois o tensionamento entre a tradição e o contemporâneo produz perguntas e vivências em que algo pode colocar-se como novidade, na oportunidade ímpar do tempo/espaço da educação escolar. O ensino da arte, na medida em que permite abertura de diferentes "janelas", contribui para a presença do outro, pois mostra paisagens inusitadas e, assim, desconstrói visões petrificadas, permitindo o arejamento do pensar, oportunidade singular para a alteridade acontecer; momento no qual o ético e o estético colocamse como uma referência fundamental do viver humano.

Contribuições dos autores: concepção e desenho, aquisição de dados, análise e interpretação dos dados, redação do artigo, revisão crítica de conteúdo intelectual importante. A autora leu e aprovou a versão final do manuscrito.

Aprovação Ética: Não aplicável.

Agradecimentos: Não aplicável.

\section{REFERÊNCIAS}

Azevedo, F. A. G. (2009). A arte possibilita ao ser humano repensar suas certezas e reinventar seu cotidiano. In: Barbosa, A. M. \& Coutinho, R. G. (org.). Arte/educação como mediação cultural e social. São Paulo: Editora Unesp, p. 335-346.

Barbosa, A. M. (2009). Mediação cultural é social. In: Barbosa, A. M. \& Coutinho, R. G. (org.). Arte/educação como mediação cultural e social. São Paulo: Editora Unesp, p. 13-22.

Brayner, F. (2008). Educação e republicanismo: experimentos arendtianos para uma educação melhor. Brasília, DF: Líber Livro. 
Boufleuer, J. P. \& Johann, M. R. (2016). A estética como possibilidade de alargamento do horizonte da ética: intercomplementaridades formativas. In: Rajobac, R., Bombassaro, L.C., \& Goergen, P. (org.). Experiência formativa e reflexão. Caxias do Sul: Educs.

Charlot, B. (2013). Da relação com o saber às práticas educativas. 1. ed. São Paulo: Cortez.

Johann, M. R. \& Fensterseifer, P. E. (2021). Giro hermenêutico \& outros escritos. Cruz Alta: Ilustração.

Flicklinger, H-G. (2000). Da experiência da arte à hermenêutica filosófica. In: Almeida, C. L. S., Flicklinger, H-G., \& Rohden, L. (200). Hermenêutica filosófica. Nas trilhas de Hans-Georg Gadamer. Porto Alegre: EDIPUCRS, p. 27-59

Flicklinger, H-G. (2014). Gadamer e a educação. Belo Horizonte: Autêntica.

Gadamer, H-G. (1999). Verdade e método I: traços fundamentais de uma hermenêutica filosófica. Tradução Flávio Paulo Meurer. 3. ed. Petrópolis, RJ: Vozes.

Gadamer, H-G. (2000). La educación es educarse. Barcelona: Paidós.

Gadamer, H-G. (2004). Verdade e método II: complementos e índices. Tradução Enio Paulo Giachini. Revisão da tradução Márcia Sá Cavalcante Schuback. 2. ed. Petrópolis, RJ: Vozes.

Gadamer, H-G. (2010). Hermenêutica da obra de arte. Seleção e tradução Marco Antonio Casanova. São Paulo: Editora WMF; Martins Fontes.

Heidegger, M. (1989). Ser e tempo II. Tradução Márcia Sá Cavalcanti. Petrópolis; RJ: Vozes.

Hermann, N. (2002). Hermenêutica e educação. Rio de Janeiro: DP\&A.

Herman, N. (2010). a Ensaios sobre educação ético-estética. Ijuí: Editora Unijuí.

Larrosa, J. (2014). Tremores: escritos sobre experiência. Tradução Cristina Antunes e João Wanderley Geraldi. 1. ed. Belo Horizonte: Autêntica, 2014.

Mink, J. (1996). Marcel Duchamp: a arte como contra-arte. Tradução Zita Morais. Köln: Taschen.

Melo e Souza, R. (1988). A ética concriativa de Gadamer. Revista TB, 94, 69-86.

Vatimo, G. (1996). Introdução a Heidegger. Tradução João Gama. 10. ed. Lisboa: Instituto Piaget.

Recebido: 29 Setembro 2020 | Aceito: 2 Fevereiro 2021 | Publicado: 17 Março 2021 